\title{
The WebSEM in K-12 Classrooms: Lessons Learned
}

\author{
L.S. Chumbley, D.J. Eisenmann*, A.E. Chumbley, T. Frizeli", ,T. Andre $\dagger$ and C.P. Hargrave
}

Iowa State University, Materials Science and Engineering Department, Ames, IA 50011

${ }^{\dagger}$ Iowa State University, Department of Curriculum and Instruction, Ames, IA 50011

* Now with the Center for Nondestructive Evaluation, Ames, IA 50011

The WebSEM is a scanning electron microscope (SEM) that provides teachers and students in K12 classrooms with the ability to conduct on-line investigations. Jointly developed by RJ Lee Group and Iowa State University, the WebSEM is based on the "Personal SEM" (PSEM) marketed by ASPEX (formerly RJ Lee) Instruments [1]. A web-based interface allows students to move samples, change magnification, adjust contrast and brightness, take pictures, and conduct chemical studies using the energy dispersive spectrometer (EDS) which is integrated into the system.

In operation, a computer server accepts java commands from the web interface, translates them into instrument commands and passes them to the PSEM for execution, then receives the updated image from the PSEM for transmission over the internet, Fig 1. Initial lessons with the system were very disappointing. Although the system functioned well it was found to be too confusing for many teachers and students, and few lessons were conducted. Improvements were identified to increase system reliability while also making it easier to operate. Commands and functions deemed un necessary for operators encountered in education were eliminated in a "second generation" server and web-interface developed specifically for K-12 instruction, Fig 2 [2]. This interface is reliable, easy to use, and teachers and students require little instruction to become proficient.

Recent efforts have been aimed at increasing the number of teachers using the WebSEM. These efforts have included 1) introducing the WebSEM to pre-service teachers at ISU through their science methods classes, 2) conducting live demonstrations of the WebSEM at conferences held for science teachers, and 3) conducting on-campus workshops for science teachers and education agency science coordinators, Fig. 3. A number of sample lesson plans have also been developed as an aid to teachers and are available for use. Finally, a short videotape showing the actually WebSEM and explaining the operation of the instrument is also available for teachers to show in their classrooms.

As a result of these actions the use of WebSEM has increased dramatically, such that in Fall 2001 approximately 2-3 sessions were conducted each week. This indicates that getting teachers to accept and use the SEM in their classroom is more dependent upon having good support for the teacher than it is on having the latest technology for delivering the image. [3]

References

[1] L.S. Chumbley, et al., "Project ExCEL - Web-based SEM for K-12 Education," to be published, J Eng Ed, April, 2002.

[2] L. S. Chumbley, et al., "Development of a Web-based SEM Specifically for K-12 Education," Micro Res. and Tech., 56, \#6, March, 2002.

[3] This work is being conducted in cooperation with G. Casuccio and D. Kritikos of RJ Lee Instruments and is partially support by Qwest Inc. and the National Science Foundation. 


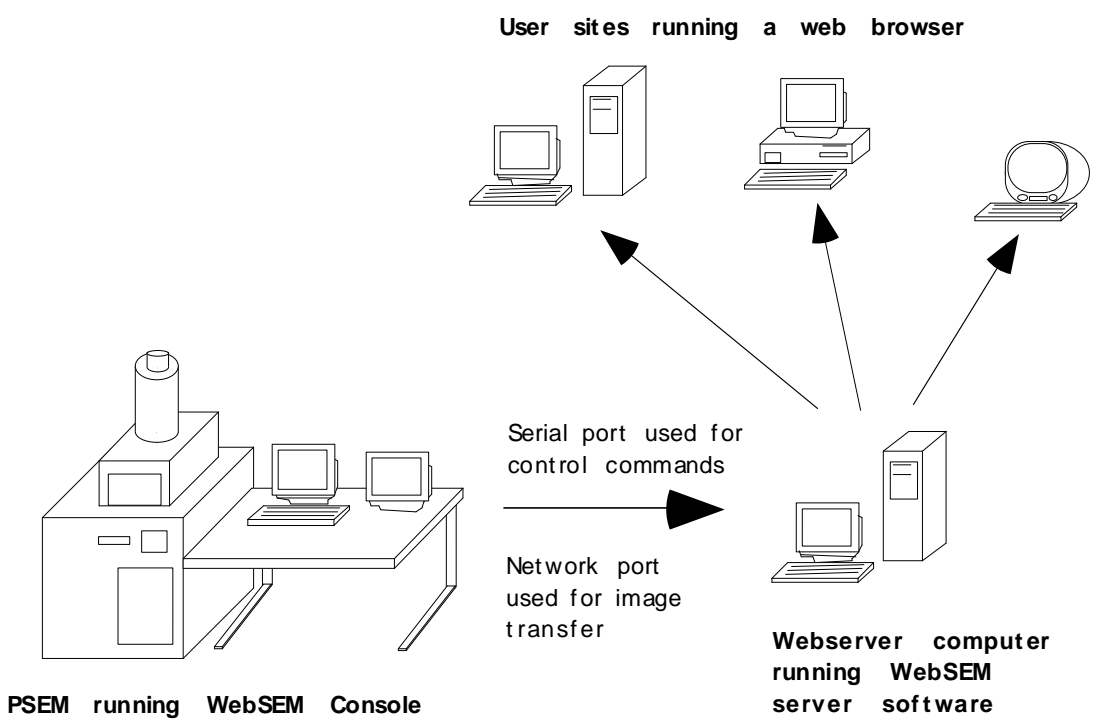

Figure 1: Schematic of the system.

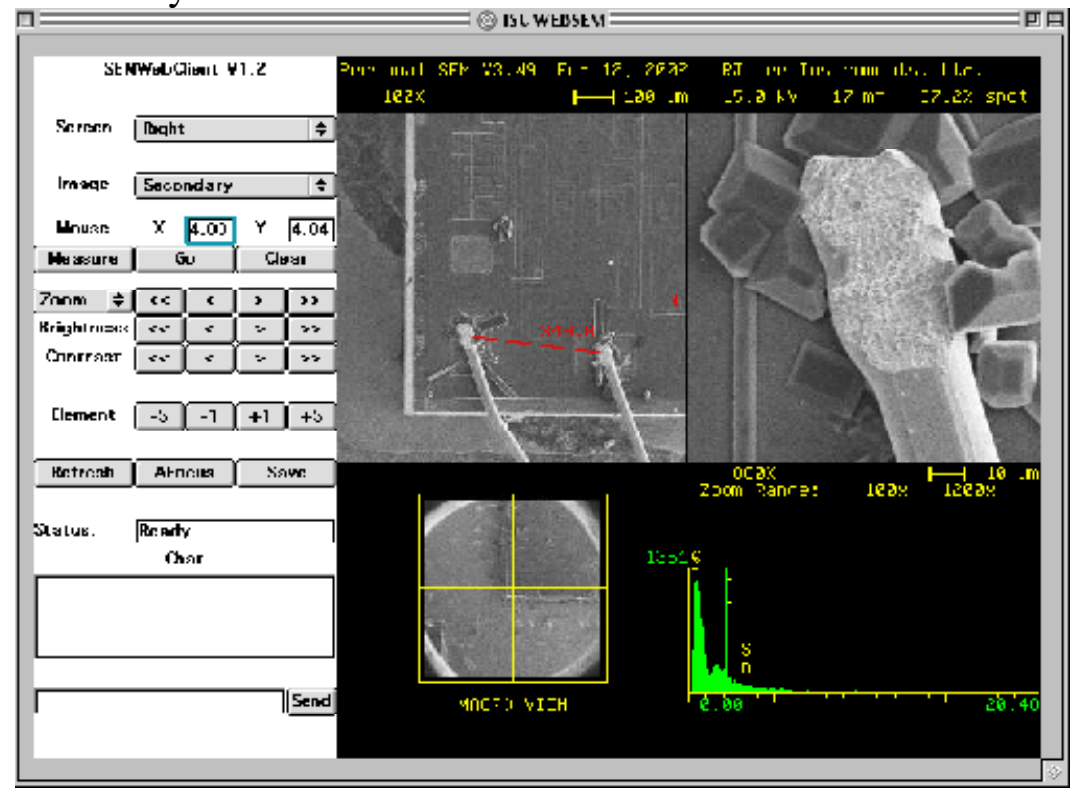

Figure 2: WebSEM console showing imaging, EDS, and measuring features.

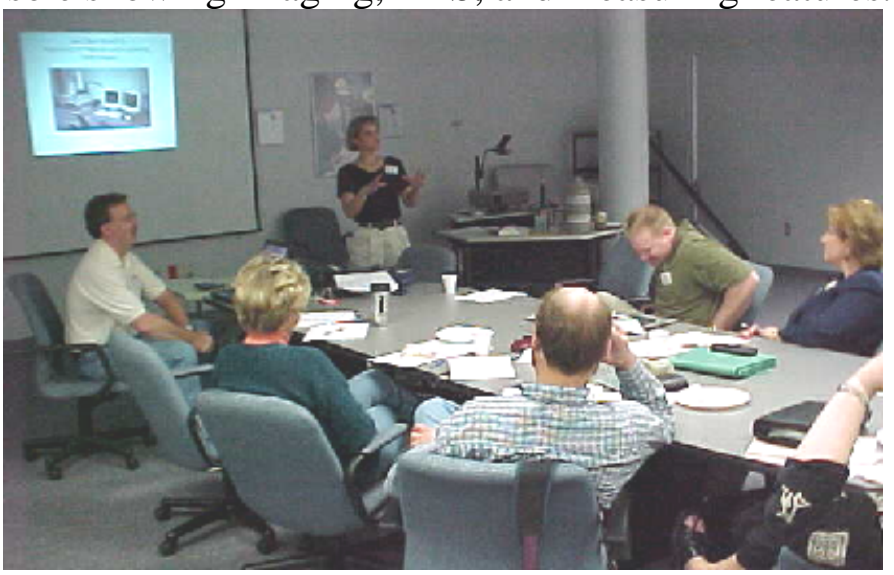

Figure 3: Teachers attending workshop at ISU on WebSEM. 